\title{
O TRABALHO DAS PROFESSORAS NA EDUCAÇÃO INFANTIL E A APRENDIZAGEM DA CRIANÇA COM SCZV
}

\author{
Fabíola Mônica da Silva Gonçalves \\ Universidade Estadual da Paraíba - UEPB \\ francesfabiola@gmail.com \\ Bruna Fernanda Ferreira Fernandes \\ Universidade Estadual da Paraíba - UEPB \\ fernandes.brunaff@gmail.com
}

Fecha de Recepción: 9 Marzo 2019

Fecha de Admisión: 30 Abril 2019

\section{RESUMO}

Este estudo focaliza a dimensão subjetiva de professoras da educação infantil, que necessitam pensar e planejar uma prática pedagógica inclusiva, com vistas a integrar à turma regular e às crianças com Síndrome Congênita do Zica vírus (SCZv), pois consideramos que o direito à aprendizagem é fundamental. Assim, questionou-se: Sobre a aprendizagem das crianças com SCZv, o que refletem esses professores? Como objetivos pensamos em: (i) apreender os sentidos e significados que estes profissionais produzem acerca do processo de desenvolvimento e aprendizagem das crianças com SCZv inseridas em escolas da rede municipal de ensino de Campina Grande, e; (ii) acompanhar e registrar a rotina pedagógica de professoras da educação infantil da rede municipal de ensino de Campina Grande, que atendem crianças com SCZv. Daí, foi realizado Estudos de Caso Múltiplos e para a análise, sendo configurada na abordagem qualitativa de pesquisa. Para análise dos dados, fez opção pela perspectiva histórico-cultural vigotiskiana e colaboradores contemporâneos. Os resultados reafirmam a relevância da formação continuada nesse segmento de ensino-aprendizagem e um trabalho pedagógico que favoreça um planejamento metodológico dinâmico, criativo com vistas à promoção do desenvolvimento integral da criança com SCZv.

Palavras-chave: trabalho do professor; crianças com SCZ; desenvolvimento integral; aprendizagem

\section{ABSTRACT \\ The work of teachers in early childhood education and the learning of the child with CZS. This study focuses the subjective dimension of teachers of the early childhood education that need to think and plan an inclusive pedagogical practice aiming integrate to the regular classroom and to children with Congenital Zika virus Syndrome (CZS) because of we considerate that the right to learning is fundamental. Thus, was questioned about the learning of the children with CZS, what these teachers reflect? As objective we thought: (I) Learn the senses and meanings that these pro-}




\section{O TRABALHO DAS PROFESSORAS NA EDUCAÇÃO INFANTIL E A APRENDIZAGEM DA CRIANÇA COM SCZV}

fessional make about the process of development and the learning of the children with CZS, inserted in public schools of the county of Campina Grande and (II) follow and register the pedagogical routine of the teachers of the early childhood education with CZS. Then, was realized Studies of Multiple Cases for the analyses, configurated in the qualitative approach of research. The data analysis has opted the Vygotskian historical-cultural perspective and contemporary contributors. The results reaffirm the relevance of the continuum formation in this segment of teaching-learning and pedagogical work that promotes dynamic methodological planning, creative with aiming the promoting of the integral development of the children with CZS.

Keywords: teacher work; children with CZS; integral development; learning

\section{INTRODUÇÃO}

Vigotski (2011) ao tratar do desenvolvimento psíquico das crianças com deficiência explica que este processo acontece por caminhos indiretos, uma vez que são impedidos pela via direta. Mas, ressalta 0 autor, à medida que esses caminhos indiretos são constituídos na vida social com as práticas culturais, acabamos por não perceber como o desenvolvimento está se consolidando em termos do aprendizado das exigências escolares e com isso, deixamos de lado um vasto manancial de desenvolvimento das pessoas com deficiência.

Conforme essa perspectiva de desenvolvimento humano, é substancial, para uma escolarização inclusiva que realize 0 trabalho pedagógico a partir da vivência cultural dos estudantes com deficiência, compreender como se constituem suas práticas sociais e como agem diante dos desafios educacionais para que se pense em propostas pedagógicas que articulem os inúmeros caminhos indiretos construídos no cotidiano dessas pessoas com as contingências formais de ensino-aprendizagem presentes na escola.

Em consonância com a concepção vigotskiana de desenvolvimento da pessoa com deficiência e afirmando a atualidade desse pensamento para à educação inclusiva, há autores que destacam a importância de pensar e planejar metodologias de ensino e aprendizagem com foco nas potencialidades metodológicas que favoreçam essas pessoas nas práticas pedagógicas das quais participam na escola. Além disso, esses autores discutem sobre a necessidade de formação inicial e continuada de professor na temática da educação inclusiva, tanto em termos teóricos, metodológicos como no conhecimento e discussão das políticas educacionais relacionadas a essa área. Contudo deixam claro que esse processo de construção de conhecimento na área da educação inclusiva ainda há muito que avançar. (Padilha, 2015; Barroso, 2018 \& Vegetti, 2018)

Na tentativa de colaborar com a pesquisa no campo da formação do professor na área da educação inclusiva, o trabalho em tela faz parte de um estudo empírico mais amplo acerca da inserção da criança com a Síndrome Congênita do Zica Virus (SCZv) no sistema público de ensino municipal na cidade de Campina Grande, localizada no estado da Paraíba no Nordeste do Brasil. Para França et. al. (2018), a Síndrome Congênita do Zika Vírus (SCZv) compreende um conjunto de sinais e sintomas apresentados por crianças nascidas de mães infectadas por esse vírus durante a gestação. $A$ SCZv também pode incluir alterações oculares, desproporção craniofacial e algumas deformidades articulares e de membros. Contudo, conforme esses autores, ainda não se sabe precisar a extensão do espectro e as consequências da SCZv para a saúde e a esperança de vida das crianças acometidas, embora seja notável a gravidade dos casos, com evidência de prejuízos no crescimento e no desenvolvimento infantil.

Segundo Reis (2015), o Ministério da Saúde declarou o registro epidemiológico de 1.761 casos suspeitos de SCZv, em 422 municípios de 14 estados brasileiros. Em razão da epidemia desta Síndrome, foram realizados investimentos na área da saúde a fim de conhecer o comprometimento 
das crianças diagnosticadas com o SCZv, "... muitos casos de microcefalia são acompanhados de alterações motoras e cognitivas que variam de acordo com o grau de acometimento cerebral... as crianças apresentam atraso no desenvolvimento neuropsicomotor ... alguns casos, as funções sensitivas ... também são comprometidas ..." (Brasil, 2016, p. 10).

Como é possível perceber, esta Síndrome apresenta comprometimento nos campos motores, sensitivo e cognitivo das crianças, o que acarreta dificuldades no processo de escolarização em função da condição diferenciada de que dispõem para se desenvolverem e aprenderem, necessitando de uma conduta psicossocial e psicopedagógica especializada para que sejam inseridas e integradas aos sistema educacional de ensino, que leve em conta suas necessidades de aprendizagem e, sobretudo, os profissionais que fazem 0 atendimento no contexto escolar, estejam em constante formação pedagógica na área da educação das crianças com deficiências, diagnosticadas com o SCZv.

Segundo Gonçalves (2010), discutir as condições históricas de nossa sociedade implica em conhecer subjetividades diferentes, pois temos que considerar a compreensão diversificada, "... decorrente de processos multideterminados, complexos e carregados de historicidade ..." (p. 20). Assim, as políticas públicas visam a superação da desigualdade social, a qual limita 0 exercício pleno da cidadania. Desta maneira, é fundamental tomar como questão central a subjetividade no processo investigativo, haja vista que 0 sujeito diz o que lhe afeta em um dado contexto sócio-histórico e reflexiona possibilidades de mudança qualitativa com vistas a melhoria das condições de vida no plano das atividades sociais globais.

Diante de tal posicionamento, esse estudo focaliza a dimensão subjetiva do professor da educação infantil, que necessita pensar e planejar uma prática pedagógica inclusiva, com vistas a integrar a turma de alunos que se encontra em níveis de desenvolvimento e necessidades especiais heterogêneas nesta etapa inicial da educação básica. Sobretudo, no atendimento educacional às crianças com SCZv, pois o direito à aprendizagem, e, por conseguinte, à educação, é universal e democrático, de acordo com a legislação educacional brasileira (Lei n. 9.394, 1996; Brasil, 2012; 2014).

Dounis e Fumis (2016), enfatizam que um dos componentes principais para a efetivação de uma educação inclusiva, é a figura do professor. Dounis (2013) ao realizar uma revisão de literatura, traz a reflexão de Souza (2006) sobre a educação inclusiva e a figura do professor como agente central no desenvolvimento de uma escola inclusiva. E, ainda, Dounis (2013) salienta que, parte das pesquisas encontradas, ponderam que a ação do professor deve integrar uma equipe multiprofissional, e, com isso, têm-se a necessidade de um projeto coletivo mais amplo, sendo este instrumento de suma importância para melhorar as condições gerais de trabalho nas escolas, a partir da implementação das políticas de inclusão e formação continuada já existentes.

Para Fernandes, Magalhães e Bernardo (2009), em função das demandas atuais na organização curricular e pedagógicas inerentes ao processo de ensino, exige-se mudanças nos saberes e fazeres dos docentes, configurada por versatilidade de estratégias para alcançar os objetivos de aprendizagem em uma turma heterogênea. No entanto Melo, Martins e Pires (2005) e Manzini (2007), com base nos discursos dos professores, acentuam que estes profissionais não se sentem preparados para oferecer propostas pedagógicas efetivas a essa clientela nas salas de aula regulares. Ademais, sobre a formação do professor na perspectiva da educação inclusiva Hernández-Amorós, Urrea-Solano, Fernández-Sogorb e Aparicio-Flores (2018) afirmam que a formação do professor deve está pautada no ensino que se assente sobre uma aprendizagem contextualizada, combinando o processo experiencial e pessoal dos estudantes com vistas a assegurar uma educação democrática e de qualidade.

Para a Convenção sobre os Direitos das Pessoas com Deficiência (Brasil, 2011), pessoas com 


\section{O TRABALHO DAS PROFESSORAS NA EDUCAÇÃO INFANTIL E A APRENDIZAGEM DA CRIANÇA COM SCZV}

deficiência apresentam impedimentos por tempo indeterminado de natureza física, mental, intelectual ou sensorial, que acarretam barreiras na participação plena e efetiva na sociedade em igualdades de condições com as demais pessoas (Artigo 1). Ainda neste documento, acerca das obrigações gerais (Artigo 4), têm-se que os Estados se comprometem a assegurar e promover o pleno exercício de todos os direitos humanos e liberdades fundamentais para todas as pessoas com deficiência, sem qualquer tipo de discriminação por causa de sua deficiência E, em específico, encontra-se disposta na 'alinha i', que o Estado deve "promover a capacitação em relação aos direitos reconhecidos pela presente Convenção dos profissionais e equipes que trabalham com pessoas com deficiência, de forma a melhorar a prestação de assistência e serviços garantidos por esses direitos" (p. 30).

É, a partir desta obrigação geral dos entes federativos (união, estados e municípios) com a formação dos profissionais que atuam na educação das crianças com SCZv, que esse estudo, se debruçou e teve o seguinte questionamento de base: sobre a aprendizagem das crianças com SCZv, o que refletem esses professores? Para tal, como objetivos pensamos em: (i) apreender os sentidos e significados que estes profissionais produzem acerca do processo de desenvolvimento e aprendizagem das crianças com SCZv inseridas em escolas da rede municipal de ensino de Campina Grande, e; (ii) acompanhar e registrar a rotina pedagógica de professoras da educação infantil das creches da rede municipal de ensino de Campina Grande, que atendem crianças com SCZv.

\section{MÉTODO}

Foi realizado Estudos de Casos Múltiplos de cunho qualitativo com abordagem sócio-histórica (Freitas, 2002; 2010), em três creches da rede municipal de Campina Grande que atendem crianças com SCZv. Assim, assumimos esse delineamento de pesquisa que segundo Yin (2001), visa à investigação de um fenômeno contemporâneo dentro do contexto de vida real, principalmente quando os limites entre 0 fenômeno e o contexto não estão claramente definidos, possibilitando um aprofundamento científico sobre 0 objeto de pesquisa. Destaca-se ainda que a pesquisa, segue a perspectiva epistemológica de Vygotsky (1996) e Vigotski (2004; 2010). Contudo, destacamos que essa investigação contou com apoio financeiro do Programa de Incentivo à Pós-Graduação e Pesquisa (PROPESQ) da Universidade Estadual da Paraíba (UEPB).

Para conhecer os discursos dos professores sobre o trabalho pedagógico e sobre o processo de desenvolvimento e aprendizagem das crianças com SCZv, foram realizadas quatro entrevistas com professoras que atuam nas creches participantes do estudo e que tem crianças com a SCZv matriculadas. Além disso, foram realizadas duas observações em sala de aula para acompanhar e registrar a rotina pedagógica de uma professora da educação infantil de uma das creches da rede municipal de ensino de Campina Grande, cuja sala de aula, tinha duas crianças com SCZv.

As observações permitiram o acesso ao contexto imediato das condições do ensino como propulsor do desenvolvimento e da aprendizagem destas crianças. Ademais, para 0 andamento da pesquisa, foram providenciados todos os procedimentos éticos previstos na Resolução 466/12 do Concelho Nacional de Saúde - Ministério da Saúde, tendo sido aprovado e registrado pelo Certificado de Apresentação para Apreciação Ética - CAAE - no 01312018.6.0000.5175.

Neste sentido, encontram-se disponíveis no quadro a seguir, a formação profissional e o tempo de experiência pedagógica das professoras participantes à época da pesquisa nomeadas de modo fictício para fins de preservação do sigilo da identidade civil. 
Quadro 1: Formação acadêmica e experiência profissional das professoras

\begin{tabular}{|l|l|}
\hline Professora Acácia & $\begin{array}{l}\text { Graduanda em Pedagogia; professora efetiva da rede municipal } \\
\text { de ensino; possui } 20 \text { anos de experiência profissional como } \\
\text { professora; } 9 \text { anos de experiência como professora da educação } \\
\text { infantil; experiência com berçário (faixa etária de } 4 \text { meses a } 1 \text { ano } \\
\text { e } 11 \text { meses) e com o maternal (faixa etária de } 2 \text { anos a } 3 \text { anos e } \\
11 \text { meses) }\end{array}$ \\
\hline Professora Dália & $\begin{array}{l}\text { Graduada em Letras; professora efetiva da rede municipal de } \\
\text { ensino; possui } 21 \text { anos de experiência profissional como } \\
\text { professora; } 10 \text { anos de experiência como professora da educação } \\
\text { infantil; experiência com berçário (faixa etária de } 4 \text { meses a } 1 \text { ano } \\
\text { e } 11 \text { meses) e com o maternal (faixa etária de } 2 \text { anos a } 3 \text { anos e } \\
11 \text { meses) }\end{array}$ \\
\hline Professora Petúnia & $\begin{array}{l}\text { Graduada em Pedagogia e em Psicologia; Especialização em Sala } \\
\text { de Atendimento Educacional Especializado AEE, e em formação } \\
\text { do educador, supervisão e orientação; professora efetiva da rede } \\
\text { municipal de ensino; possui } 10 \text { anos de experiência como } \\
\text { professora e seis } 6 \text { anos de experiência como professora da } \\
\text { educação infantil; experiência com berçário (faixa etária de } 4 \\
\text { meses a } 1 \text { ano e } 11 \text { meses) e com o maternal (faixa etária de } 2 \\
\text { anos a } 3 \text { anos e } 11 \text { meses). }\end{array}$ \\
\hline Professora Violeta & $\begin{array}{l}\text { Graduada em Pedagogia; professora efetiva da rede municipal de } \\
\text { ensino; possui } 23 \text { anos de experiência como professora e } 12 \text { anos } \\
\text { de experiência como professora da educação infantil; experiência } \\
\text { com berçário (faixa etária de } 4 \text { meses a 1 ano e 11 meses) e com } \\
\text { o maternal (faixa etária de } 2 \text { anos a } 3 \text { anos e 11 meses). }\end{array}$ \\
\hline
\end{tabular}

Na turma do maternal II, grupo participante da pesquisa, haviam 25 crianças entre 3 anos a 3 anos e 11 meses, sendo essa a turma observada na qual as duas crianças Iris e Jasmim (nomes fictícios) estavam matriculadas. Iris estava com 3 anos de idade completos e Jasmim e com 3 anos e 2 meses. Essa creche funciona em tempo integral das 7 às $17 \mathrm{~h}$.

\section{RESULTADOS E DISCUSSÃO}

A análise que se segue contemplou duas dimensões interconectadas, a saber: (i) as reflexões das professoras da educação infantil sobre a aprendizagem e 0 desenvolvimento das crianças com SCZv, que trabalham em escolas da rede municipal de ensino de Campina Grande/PB, e: (ii) e a prática pedagógica vivenciada em uma turma da educação infantil de uma escola pública da referida rede de ensino que atende duas crianças com a SCZv.

\section{Aprendizagem e desenvolvimento das crianças com a SCZv na perspectiva das professoras da educação infantil}

Na busca pela compreensão de como as professoras refletem acerca da aprendizagem e do desenvolvimento das crianças com a SCZv, a partir da vivências pedagógicas que tiveram e ainda tem com essas crianças e com base no posicionamento de Vigotski (2011) sobre os caminhos indiretos do desenvolvimento da pessoa com deficiência, é que nos impulsionou para investigar o tra- 


\section{O TRABALHO DAS PROFESSORAS NA EDUCAÇÃO INFANTIL E A APRENDIZAGEM DA CRIANÇA COM SCZV}

balho de quatro professoras que atuam na educação infantil e que tem na sua turma uma ou até duas crianças com a SCZv e que se dispuseram a colaborar com a nossa pesquisa voluntariamente, cuja formação e tempo de experiência profissional estão descritas no Quadro 1 da seção anterior.

Sendo assim, foi possível identificar, a partir dos relatos das professoras sobre 0 trabalho pedagógico com essas crianças, alguns indícios que nos permitiu perceber as concepções que elas possuem a respeito do processo de desenvolvimento e aprendizagem dessas crianças. Ademais foi possível entender se o trabalho realizado está pautado ou não na perspectiva da educação inclusiva, bem como 0 entendimento das condições socio-históricas determinantes de tal posicionamento.

Contudo, sobre o trabalho pedagógico na sala de aula essas crianças com a SCZv, foi possível perceber relatos bem heterogêneos entre as professoras que atuam em três creches da rede municipal de ensino de Campina Grande/PB do Nordeste do Brasil, como disposto no Quadro 2 adiante.

Quadro 2: Relatos das professoras sobre o trabalho pedagógico em sala de aula

\begin{tabular}{|c|c|}
\hline Professora Acácia & $\begin{array}{l}\text { "Aí como aqui não tinha muito estimulação para ela, a cuidadora } \\
\text { dela pegava ela e ia para sala de estimulação do BI (Berçário I) } \\
\text { que lá tinha mais estimulação. Aí a gente aqui quase não teve } \\
\text { contato assim com ela, para saber como que tava o } \\
\text { desenvolvimento dela, a questão de fazer alguma atividade com } \\
\text { ela a gente não teve como. Os dias que ela vinha, ficava mais na } \\
\text { outra sala." } \\
\text { "Pelo menos assim, o pouco contato que eu tive quando ela tava } \\
\text { na sala, que eu tentei fazer a atividade que eu tava fazendo com } \\
\text { as outras crianças com ela... de berçário principalmente, que a } \\
\text { gente trabalha questões de pintura, mãozinha, pezinho... essas } \\
\text { coisas, quando ia pintar a mão dela era difícil ela abrir a mão. Ela } \\
\text { não abria a mão, era complicado fazer esse tipo de atividade com } \\
\text { ela. Foi pouco mesmo o contato que teve assim para fazer esse } \\
\text { tipo de atividade com ela" } \\
\text { ".... É mais complicado mesmo como trabalhar com a criança. “ }\end{array}$ \\
\hline Professora Dália & $\begin{array}{l}\text { “.... Foi toda uma expectativa, era tudo muito novo, até para a } \\
\text { gente professor. Mas a gente recebeu Iris como qualquer outra } \\
\text { criança." } \\
\text { "Eu a vejo bem incluída, porque nos momentos das atividades } \\
\text { elas sempre estão presentes, nas atividades pedagógicas ... na } \\
\text { questão pedagógica a gente sente ela muito acolhida por todos, } \\
\text { principalmente pelas outras crianças" }\end{array}$ \\
\hline Professora Petúnia & $\begin{array}{l}\text { "... a inclusão é uma coisa muito necessária, muito importante, } \\
\text { mas o preparo mesmo a gente vai aprendendo no dia-a-dia. Vai } \\
\text { vendo a necessidade dele, vai tentando... ver o que a gente pode } \\
\text { fazer para melhorar, para realmente se desenvolver e para ele, } \\
\text { realmente, estar incluso na escola, para ser uma inclusão de } \\
\text { verdade." } \\
\text { ".. acho que nós profissionais temos que ser bem mais preparados, } \\
\text { ter um acervo de material antes mesmo de chegar a criança ... } \\
\text { Claro que o professor vai buscar na internet, eu sou muito de }\end{array}$ \\
\hline
\end{tabular}




\begin{tabular}{|c|c|}
\hline & $\begin{array}{l}\text { buscar as coisas, sou muito de esperar não... mas assim um } \\
\text { profissional específico para dizer assim: "olhe a finalidade disso } \\
\text { aqui é isso, mas você pode buscar outros meios", vai dando os } \\
\text { estalos, né. A educação infantil é uma coisa muito nova e no } \\
\text { momento vai dando uns estalos na gente: "Eita! Assim acho que } \\
\text { dá certo". A gente tenta algo... não tem receita pronta, educação } \\
\text { não tem receita pronta." }\end{array}$ \\
\hline Professora Violeta & $\begin{array}{l}\text { "Porque tinha o material que a gente usava com ela, tinha uma } \\
\text { bola grande que fazia movimento com ela, tinha uns de sons } \\
\text { também que a gente fazia, entendeu? Tanto do corpo, } \\
\text { movimentos do corpo para desenvolver essa parte da } \\
\text { musculatura, essas coisas e também tinha a parte de música e } \\
\text { essas coisas para estimular a visão, a audição... a parte } \\
\text { audiovisual." } \\
\text { "No início que a gente não tinha nenhum conhecimento, a gente } \\
\text { só tinha ouvido falar, mas não tinha visto de perto como trabalhar, } \\
\text { como fazer, entendeu? Como é que nós vamos trabalhar com essa } \\
\text { criança? Para a gente era tudo novo, e a gente foi aprendendo aos } \\
\text { poucos como ia fazendo." } \\
\text { "...a turma que ela está, as atividades também têm que ser } \\
\text { pensadas para ela" }\end{array}$ \\
\hline
\end{tabular}

A partir dos fragmentos dos relatos das professoras dispostos no Quadro 2 acerca do trabalho pedagógico das crianças com a SCZv no contexto da sala de aula, podemos evidenciar alguns pontos em comum entre os relatos e alguns pontos divergentes.

No caso das possibilidades da criança com a SCZv realizarem as atividades na sala de aula em conjunto com os demais colegas da turma, identificamos passagens que evidenciam um trabalho pedagógico que se propõe a inclusão e que consideram a necessidade de conhecer primeiro a criança e suas potencialidades para iniciar com as atividades pedagógicas propriamente ditas, como podemos constatar nos fragmentos que se seguem: "...Vai vendo a necessidade dele, ... ver o que a gente pode fazer para melhorar, para realmente se desenvolver e para ele ..."(Professora Petúnia); “... Eu a vejo bem incluída, porque nos momentos das atividades elas sempre estão presentes, nas atividades pedagógicas..." (Professora Dália)“... a turma que ela está, as atividades também tem que ser pensadas para ela" (Professora Violeta). Nesse sentido, esses relatos apresentam consonância com 0 que preconiza a Convenção Internacional sobre os Direitos das Pessoas com Deficiência no tocante à educação, uma vez que o direito de aprender e de participar ativamente das atividades escolares deve ser respeitado e garantido. Além disso, respeitar a condição de aprendizagem e desenvolvimento da criança com deficiência é uma obrigação básica sobretudo, no sistema de ensino público. 0 contato inicial pelo professor é fundamental para que este se aproprie das possiblidades de aprendizagem da criança com deficiência. (Brasil, 2011, 2012, 2014; Vigotski, 2011).

No entanto, um dos relatos das participantes aponta a dificuldade em saber lidar pedagogicamente com a criança que possui a SCZv "Aí como aqui não tinha muito estimulação para ela ... a questão de fazer alguma atividade com ela a gente não teve como ..." (Professora Acácia). Esse relato nos remete a pensar essencialmente em elementos que possam determinar esse tipo de con- 


\section{O TRABALHO DAS PROFESSORAS NA EDUCAÇÃO INFANTIL E A APRENDIZAGEM DA CRIANÇA COM SCZV}

duta pedagógica. 0 primeiro elemento, diz respeito a questão da organização do tempo e dos espaços de aprendizagem no currículo da educação infantil, que se faz necessário mudança metodológica em termos das estratégias de ensino que visam efetivar a aprendizagem em uma turma heterogênea. Já o segundo elemento, está relacionada a formação continuada do professor que atua em salas de aulas inclusivas. A escassez de formação continuada de professor nesse campo de atuação, é materializada na prática pedagógica a medida que não se buscam alternativas educativas para que a criança com a SCZv participe mais ativamente do processo pedagógico em sala de aula e, por conseguinte que as suas potencialidades para aprender e se desenvolver sejam garantidas. (Melo, Martins e Pires, 2005; Manzine, 2007; Hernández-Amorós, Urrea-Solano, Fernández-Sogorb \& Aparicio-Flores, 2018).

Ao mesmo tempo que do ponto de vista pedagógico, percebemos em alguns relatos existir uma postura mais separatista do que inclusiva entre os colegas da turma e a criança com a SCZv, identificamos alguns elementos que podem contribuir significativamente com uma maior participação dessas crianças nas turmas que estão inseridas. Um desses elementos é a figura do cuidador da criança com a SCZv que trabalha, dentre outras atribuições, com a responsabilidade de estimular 0 campo sensorial dessas crianças em função dos comprometimentos de saúde que possuem e nos graus de severidade que são acometidas pela doença (França, et. al. 2018). E o outro aspecto que pensamos interferir nessa situação é a atuação da família em relação ao acompanhamento sistemático dessas crianças aos tratamentos de saúde com a equipe multidisciplinar de saúde que se faz necessário para o desenvolvimento dessas crianças.

No posicionamento analítico tomado acima, será que essas crianças são de fato assistidas com regularidade pela equipe multidisciplinar de saúde? Abre-se, portanto um novo aspecto que carece de aprofundamento com vistas a se perceber se aquelas crianças que estão tendo mais êxito no seu desenvolvimento educacional, são de fato aquelas que possuem um grau de severidade da SCZv mais ameno em relação aquelas crianças que não avançam muito do ponto de vista da aprendizagem escolar? Ou se o fator da assistência pela equipe multiprofissional de saúde com ênfase na estimulação sensorial tem sido negligenciado pela família dessas crianças?

Sobre a questão da estimulação sensorial das crianças com a SCZv em sala de aula, alguns relatos revelam acontecer esse tipo de conduta pedagógica com vistas a proporcionar o desenvolvimento dessas crianças por conta de disporem de materiais para efetuarem o trabalho de estimulação "... tinha uma bola grande que fazia movimento com ela ... movimentos do corpo para desenvolver essa parte da musculatura, essas coisas e também tinha a parte de música e essas coisas para estimular a visão, a audição."(Professora Violeta). Por outro lado, identificamos um relato que informa da necessidade de um investimento maior em formações pedagógicas que abordem explicações de como lidar com essa criança em termos pedagógicos e a disponibilidade de recursos para o desenvolvimento do trabalho educativo “... acho que nós profissionais temos que ser bem mais preparados, ter um acervo de material antes mesmo de chegar a criança ... mas assim um profissional específico para dizer assim: "olhe a finalidade disso aqui é isso"..." (Professora Petúnia). Nesse segundo relato, a professora também deixa claro que o professor busca informações, faz pesquisas, mas que também se faz necessário à presença de outros profissionais que auxiliem 0 trabalho do professor por meio de ações voltadas à formação pedagógica em serviço do professor que atende a criança com a SCZv na turma que leciona.

Assim, embora todas as escolas participantes da pesquisa sejam da mesma rede de ensino, podemos perceber diferenças em termos de recursos didáticos disponíveis para o professor realizar um trabalho pedagógico voltado para as necessidades da criança com a SCZv umas parecem estarem mais aparelhadas do ponto de vista dos recursos, enquanto outras não. Além disso, a 
carência por um trabalho de formação continuada em serviço do professor que trabalha na perspectiva inclusiva, apesar de todo um aparato legal para assegurar a inclusão educacional da criança com deficiência, ainda tem muito que caminhar para garantir equidade e qualidade pedagógica no seu processo de desenvolvimento e aprendizagem escolar. (Padilha, 2015; Barroso, 2018; Vegetti, 2018).

Em acordo com Dounis e Fumis (2016) Doumis (2013) e Souza (2006), essa pesquisa reafirma ser fundamental investir na formação do professor da educação inclusiva por ser este o profissional que lida diretamente, no cotidiano da sala de aula com as crianças que apresentam algum tipo de deficiência. Inclusão social é um ato educativo que prescinde de um processo constate de formação pedagógica tanto no campo da teorização, da legislação que assegura o direito de aprender a essas crianças e dos aspectos metodológicos que se ocupam em lançar luz ao respeito da diferença nos processos de desenvolvimento e aprendizagem, considerando a diferença como princípio fundamental e norteador do trabalho pedagógico do professor.

Para darmos continuidade com nossas análises acerca da aprendizagem e do desenvolvimento da criança com a SCZv, abordamos adiante alguns elementos capturados pelo registro observacional realizado em uma das salas de aula participante da pesquisa.

\section{A prática pedagógica na turma de duas crianças com SCZv da educação infantil}

Antes de adentrar nos registros das observações realizadas, pontua-se adiante sobre a rotina pedagógica em sala de aula da turma do maternal II da creche participante da pesquisa. Desse modo, a rotina na creche começa já pela manhã com o responsável pela criança, com a SCZv, dando os devidos remédios. Nos primeiros encontros de aproximação com o campo da pesquisa, foi informado que essa medida foi para promover o melhor aproveitamento das crianças com SCZv na creche, visto que ao tomar os remédios em casa, a criança já chegava sonolenta na creche e perdia-se a oportunidade de interações em sala de aula durante a manhã inteira. Quando as crianças estão estabilizadas do ponto de vista clínico, elas participam das rotinas pedagógicas, se fazendo presentes em todo e qualquer espaço que as outras crianças também estejam, com exceção do momento de alimentação, banho e sono. Foi percebido, de modo geral, que no turno da manhã a rotina delas é mais calma e menos produtiva, devido justamente a dose de remédio dada ao chegar na creche, carecendo de um tempo maior destinado ao sono.

0 tempo das crianças com a SCZv em sala de aula é menor em relação ao tempo das outras crianças, principalmente porque o processo da alimentação é mais demorado; ainda sim, a alimentação é dada na sala de aula igual com as outras crianças. Como a creche funciona em período integral, todas as crianças têm a hora do sono. Após a hora do sono e do lanche, começam as atividades pedagógicas diversificadas como pintura, desenho, colagem, contação de história e música. Os momentos de contação de história e música foram os mais observados na rotina pedagógica dessa turma, e nesses momentos tanto Iris como Jasmim se engajaram nas situações de aprendizagem com sorrisos e olhares. Para efeito ilustrativo, serão destacas duas rotinas pedagógicas das quais uma das crianças, a Iris participou.

Na primeira observação, Iris estava no berçário com a cuidadora realizando as atividades de estimulação tátil com toques nas extremidades e na face, e estimulação sonora que a cuidadora faz com a boca e ela tenta reproduzi-los, conseguindo algumas vezes. Pode-se evidenciar que Iris está bem adaptada a rotina pedagógica da educação infantil, uma vez que esse já é o seu segundo ano na escola e ela possui uma boa frequência. Com efeito, percebemos que essa criança tem recebido 0 apoio necessário, no ambiente escolar, por parte da cuidadora para que Iris encontre caminhos facilitadores de aprendizagem durante seu percurso de desenvolvimento educacional. (Brasil, 2011; 2012; 2014). 


\section{O TRABALHO DAS PROFESSORAS NA EDUCAÇÃO INFANTIL E A APRENDIZAGEM DA CRIANÇA COM SCZV}

Ao chegar na sala de aula, Iris é recebida com muito carinho pelos colegas que sempre querem fazer carinho e estar perto dela, nesses momentos a cuidadora sempre está ao lado sendo o agente facilitador desse processo. Como era aniversário de Iris, a cuidadora propôs que a turma cantasse parabéns para ela, então, os alunos se posicionaram ao redor da cadeira de Iris e cantaram parabéns, junto dela estava a professora e a cuidadora, enquanto Iris sorria aparentando nenhum incômodo com o barulho da comemoração com os colegas, reafirmando sua evolução quanto a tolerância a barulhos. Neste dia, Iris foi para casa mais cedo por conta do seu aniversário, pois a família também havia preparado uma festinha para ela.

0 segundo registro da observação da rotina pedagógica da turma do maternal II, também só contou com a participação de Iris, pois Jasmim estava em processo de mudança para outra creche da rede municipal de ensino. Assim, incialmente, observou-se que Iris ao entrar na sala de aula foi acompanhada com muita atenção pelos colegas. Eles chegam perto, abraçam, beijam e conversam. E este momento é sempre acompanhado da cuidadora que é a facilitadora desse processo de interação. Há sempre o comentário de que as crianças não se importam com a condição de Iris e seus colegas constantemente fazem pausas nas brincadeiras para fazer carinho e perguntar a cuidadora sobre ela. No entanto, percebeu-se que interação acontece, em diversos níveis, com as mais diversas pessoas que estão na creche, mas a inclusão parece ficar em segundo plano, levantando um alerta sobre a importância de se construir coletivamente caminhos alternativos de aprendizagem e processos de mediação pedagógicas que favoreçam a real inclusão das crianças com deficiência no contexto educativo da sala de aula. (Vigotski, 2011; Fernandes, Magalhães \& Bernardo, 2009).

No tocante a articulação pela professora da participação de Iris nas atividades pedagógicas propostas, observou-se que estas se configuram em tarefas de cunho sensorial, como as que envolvem pintura e música. Neste dia foi sugerido que as crianças trabalhassem com colagem de algodão para formar a penugem de uma ovelha previamente impressa. Nesse trabalho Iris precisou da mediação de um outro mais experiente que no caso foi a cuidadora que se faz presente. Ela espaIhou cola nas mãos de Iris com o propósito de levá-la a sentir uma textura diferente, e Iris nesses momentos sorri. Depois, junto da mão da cuidadora, ela pega os algodões e cola na figura. Iris se mostra engajada nesse processo à medida que tem reações de adesão a atividade.

Atividades como essa da colagem são escassas, visto que nos outros dias de visita a esta creche, não houve momentos pedagógicos como esse que Iris pode se engajar mais diretamente no processo. Há também a uma questão importante a se considera, é a quantidade de crianças na sala e o papel do cuidador. Neste dia tinha mais ou menos 18 crianças na sala provocando um grande empecilho para que o professor esteja mais perto da criança com a SCZv, não só por isso, mas porque a criança com SCZv tem o cuidador que está com ela grande parte do tempo, o que é extremamente necessário, haja vista as limitações motoras e por serem suscetíveis a engasgos e convulsões. Desse modo, em sala de aula, o professor pode acabar resguardando a sua função junto a esta criança à medida que ela já tem uma pessoa que Ihe auxilia (o cuidador) em todo seu dia-a-dia; enquanto a atenção do professor se volta às outras crianças em sala de aula. Esse ponto da observação nos remete a questionar os achados de Melo, Martins e Pires (2005) e Manzini (2007) sobre a insegurança dos professores em termos de sua atuação pedagógica com vistas a impulsionar 0 desenvolvimento e aprendizagem em uma sala de aula inclusiva. Sob quais condições de funcionamento e gestão das aprendizagens das crianças com deficiência e das crianças sem deficiência 0 professor trabalha? Como essas condições interferem no processo pedagógico vivenciada em uma sala de aula inclusiva?

Além disso, foi possível observar que Iris se faz presente nos lugares que a sua turma está em atividade pedagógica como a sala de leitura, o pátio e a sala de aula. Outro lugar que as crianças 
estão sempre presentes é o berçário, pois é lá que ocorre o momento do sono e muitos momentos de alimentação. 0 berçário possui uma melhor estrutura para esses momentos quando falamos da criança com SCZv, uma vez que ela dorme em berços e a sua alimentação vem da cozinha do berçário, pois lá eles já têm os instrumentos necessários para processar os alimentos, por exemplo. Em datas comemorativas quando há festas e atrações diferentes como pula-pula na creche, Iris participa desses momentos. A cuidadora de Iris informou que no dia que a creche comemorou o dia das crianças Iris se divertiu muito brincando com ela no pula-pula. E fala também que outras pessoas ficaram receosas dela fazer isso com a criança, mas ela sempre enfatiza que Iris também tem 0 direito de usufruir daquilo ali desde que com muita segurança e responsabilidade.

Outro ponto que mereceu destaque nesse registro observacional diz respeito a vivência inclusiva no cotidiano dessa sala de aula entre o professor e o cuidador com as crianças da turma. Na creche o discurso de inclusão está sempre nas pautas de conversa e esta questão sempre vem com uma ressalva, pois fala-se muito que há uma tentativa real de inclusão dessa criança nas atividades, nos ambientes, nos materiais, porém ainda há muito 0 que se melhorar. Relata-se muito da escassez de materiais didáticos que ajude nesse trabalho pedagógico e o manejo difícil em sala de aula com muitos alunos. Desse modo, a atenção do professor fica difusa no contexto de sala de aula, 0 que dificulta 0 trabalho pedagógico que é essencial para a consolidação da inclusão. Assim, a valorização da figura do professor por meio do trabalho pedagógico de qualidade que venha a realizar, depende em parte das condições materiais e educacionais que se realiza no interior das salas de aula inclusivas. (Dounis e Funis, 2016; 2013; Fernandes, Magalhães \& Bernardo, 2009).

Diante disso, afirma Gonçalves (2010), é necessário adentrar nas subjetividades a fim de que conheçamos os elementos sócio-históricos que condicionam determinadas práticas educativas que não avançam com vistas a superação das desigualdades sociais, identificar quais desses elementos impedem o desenvolvimento e aprendizagem das crianças com deficiência é fundamental, mas aliado a isso, é essencial que se produzam coletivamente caminhos pedagógicos alternativos para que a inclusão se efetive plenamente em salas de aulas inclusivas (Vigotski, 2011).

Por último, percebemos na figura da cuidadora da criança com SCZv o grande alicerce dessa inclusão, pois é ela que conhece de perto as necessidades e características daquela criança e é ela que fica junto à criança e acaba auxiliando-a nas atividades em sala de aula. Por isso, se não houver a atenção ao processo pedagógico da inclusão, a criança com a SCZv acaba se perdendo neste cotidiano à medida que apenas o estar presente na sala de aula não basta. (Brasil, 2011; 2012).

\section{CONSIDERAÇÕES FINAIS}

Diante das reflexões realizadas pelas professoras sobre 0 trabalho pedagógico que tem desenvolvido com crianças com a SCZv e a observação da rotina pedagógica de uma sala de aula inclusiva podemos tecer algumas considerações acerca dos desafios e das conquistas evidenciadas em relação aos achados dessa pesquisa.

Em primeiro lugar, ficou evidente a heterogeneidade de posicionamentos entre as professoras que participaram da pesquisa acerca de como realizar atividades que impulsionem a aprendizagem e 0 desenvolvimento dessas crianças. Há professoras que favorecem um contexto pedagógico mais fértil para a vivência inclusiva entre as crianças com deficiência e as crianças sem deficiência na sala de aula sob sua responsabilidade educativa. Por outro lado, identificamos relatos que revelam posicionamentos que corroboram com um trabalho pedagógico segregado, quase ausente, quando se trata de se colocar na posição de facilitador do processo de ensino e aprendizagem das crianças com a SCZv.

No entanto, foi percebido que alguns dos entraves para uma concretização de uma sala de aula 


\section{O TRABALHO DAS PROFESSORAS NA EDUCAÇÃO INFANTIL E A APRENDIZAGEM DA CRIANÇA COM SCZV}

inclusiva, diz respeito ao processo de formação continuada e em serviço do professor na perspectiva da inclusão, bem como de materiais pedagógicos especializados que auxiliem o trabalho do professor junto as crianças com a SCZv. Ademais, foi enfatizado um terceiro elemento dificultador de uma prática educativa inclusiva, a superlotação da sala de aula que precariza o tempo de atendimento pedagógico que a professora disponibiliza para dar atenção ao processo individual e singular que cada criança percorre no seu aprendizado e no seu desenvolvimento, levando a ter que delegar parte de suas atribuições pedagógicas no trabalho com a criança a um terceiro profissional, que no caso aqui identificado, foi a figura do cuidador.

Outro ponto a ser destacado a partir dessa pesquisa, foi a atitude das crianças sem deficiência em relação a criança com a SCZv, pois demostraram uma postura de acolhimento repleta de afeto e preocupação como bem-estar de Iris, e não demostrando comportamentos repulsivos, que caracterizam uma prática excludente, diante da presença dessa criança na rotina pedagógica da turma do maternal II. Esse achado nos remete a pensar sobre a relevância de observarmos com mais atenção esse movimento inclusivo que as crianças realizam entre si, a fim de buscarmos caminhos alternativos para a promoção do desenvolvimento e da aprendizagem na perspectiva da educação inclusiva.

Por último, fica patente a necessidade de se avançar com mais estudos dessa natureza, como já registrado por estudiosos da área da educação inclusiva, sobretudo no campo da formação continuada e em serviço do professor que atende a população estudantil com deficiência, não apenas na fase inicial do processo de escolarização, mas em todos os segmentos e níveis educacionais com vistas ao favorecimento das potencialidades pedagógicas dessas pessoas em prol de uma prática educativa democrática e cidadã.

\section{REFERÊNCIAS}

Barroso, S. M. S. (2018) Vigotski's theories on defectology: contibuitions to the especial education of the $21^{\text {st }}$ century. Educação, 42(3), 374-384. Recuperado de http://revistaseletronicas.pucrs.br/ojs/index.php/faced/article/view/31826/17615

Brasil (2011). Convenção sobre os Direitos das Pessoas com Deficiência: Protocolo Facultativo à Convenção sobre os Direitos das Pessoas com Deficiência. Brasília: Secretaria de Direitos Humanos, Secretaria Nacional de Promoção dos Direitos da Pessoa com Deficiência. Recuperado

https://www.pessoacomdeficiencia.gov.br/app/sites/default/files/publicacoes/convencaopessoascomdeficiencia.pdf

Brasil (2012). Elementos conceituais e metodológicos para definição dos direitos de aprendizagem e desenvolvimento do ciclo de alfabetização (1ㄴ, $2^{\circ} 3^{\circ}$ anos) do ensino fundamental. Brasília: Secretaria de Educação Básica. Diretoria de Currículos e Educação Integral. Coordenação Geral do Ensino Fundamental. Recuperado de: http://portal.mec.gov.br/index.php?option=com_docman\&view=download\&alias=12827-texto-referencia-consulta-publica-2013-cne-pdf\&category_slug=marco-2013-pdf\&ltemid=30192

Brasil (2014). Plano Nacional de Educação 2014-2014 [recurso eletrônico]: Lei no 13.005, de 25 de junho de 2014, que aprova o Plano Nacional de Educação (PNE) e dá outras providências. Brasília: Câmara dos Deputados, Edições Câmara, 86p. - (Série legislativo; n. 125).

Brasil (2016). Ministério da Saúde. Secretaria de Atenção à Saúde. Protocolo de atenção à saúde e reposta à ocorrência de microcefalia relacionada à infecção pelo vírus Zika. Recuperado de http://bvsms.saude.gov.br/bvs/publicacoes/protocolo_resposta_microcefalia_relacionada_infec cao_virus_zika.pdf 
Dounis, A. B (2013). Atividade docente e inclusão: as mediações da consultoria colaborativa. Dissertação de Mestrado. Universidade Federal de Alagoas. Centro de Educação. Maceió, AL, Brasil. Recuperado de http://www.repositorio.ufal.br/handle/riufal/1457

Dounis, A. B.; Fumes, N. de L. F. (2016). Formação continuada do docente para a inclusão: as mediações produzidas pela consultoria colaborativa e autoconfrontação. In W. M. J. de Aguiar, \& A. M. B. Bock. (Orgs). A dimensão subjetiva do processo educacional: uma leitura sócio-histórica (249-265). São Paulo: Cortez.

Fernandes, M. de L. C. N.; Magalhães, R. de C. B. P.; Bernardo, C. M. C (2009). Formação docente para processos de educação inclusiva: descortinando concepções. In L de R Martins, \& L. G. dos S Silva (Orgs.), Múltiplos olhares sobre inclusão (pp. 45-55). João Pessoa. Editora Universitária da UFPB.

França, G.V. A. de., Pedi, D. V., Garcia, M. H. de 0., Carmo, G. M. I. do, Garcia, L. P. (2018). Síndrome congênita associada à infecção pelo vírus Zika em nascidos vivos no Brasil: descrição da distribuição de casos notificados e confirmados em 2015-2016. Epidemiol. Serv. Saúde, 27(2), 1-12. Recuperado de: http://www.scielo.br/pdf/ress/v27n2/2237-9622-ress-27-02-e2017473.pdf

Freitas, M. T. de A (2010). Discutindo sentidos da palavra intervenção na pesquisa de abordagem histórico-cultural. In M. T. de A Freitas, \& B. S Ramos (Orgs.). Fazer pesquisa na abordagem histórico-cultural: metodologias em construção (pp. p.13-24). Juiz de Fora: Ed. Da UFJF

Freitas, M. T. de A (2002). A abordagem sócio-histórica como orientadora da pesquisa qualitativa. Cadernos de Pesquisa, (116), 21-39. Recuperado de: http://www.scielo.br/pdf/cp/n116/14397.pdf

Gonçalves, M. da G. M (2010). Psicologia, subjetividade e políticas públicas (1a ed., Coleção Construindo o Compromisso Social da Psicologia). São Paulo: Cortez.

Hernández-Amorós, M. J., Urrea-Solano, M. E., Fernández-Sogorb, A., Aparicio-Flores, M. del P (2018). Atención a la diversidad y escuela inclusiva: las actitudes del futuro profesorado. INFAD Revista de Psicología, 3(1), 147-156. Recubierto de: http://www.infad.eu/RevistalNFAD/OJS/index.php/IJODAEP/article/view/1244/1091

Lei n. 13.005, de 25 de junho de 2014. Aprova o Plano Nacional de Educação - PNE e dá outras providências. Recuperado de http://www.planalto.gov.br/ccivil_03/_at020112014/2014/lei/l13005.htm

Lei n. 9.394, de 20 de dezembro de 1996. Estabelece as diretrizes e bases da educação nacional. Recuperado de http://www.planalto.gov.br/ccivil_03/leis/19394.htm

Manzini, E. J (2007). Formação continuada do professor para atender à educação inclusiva. In: MINISTÉRIO DA EDUCAÇÃO. Secretaria de Educação Especial. Ensaios pedagógicos: educação inclusiva: direito à diversidade. Brasília: Gráfica Editora Ideal, p. 77-84.

Martins, L. de A. R., Melo, F. R. L. V. de, Pires, G. N. da L., Pires, J. (2005). Experiências de intervenção em prol da inclusão de alunos como paralisia cerebral: constatações a partir de uma pesquisa-ação. In L. de A. R. Martins, \& F. R. L. V. de Melo, \& G. N. da L. Pires, \& J. Pires (Orgs.), Inclusão: compartilhando saberes (pp. 141-148). São Paulo: Vozes.

Padilha, A. M. L. (2015). Educação inclusiva: já se falou muito sobre ela? Educ. Foco, Edição Especial, 313-332. Recuperado de https://periodicos.ufjf.br/index.php/edufoco/article/view/19686

Reis, R. P. dos (2015). Aumento dos casos de microcefalia no Brasil. Rev Med. 25(6), 88-89. Recuperado de: rmmg.org/exportar-pdf/1848/v25s6a12.pdf

Resolução n. 466, de 12 de dezembro de 2012. Aprovar as seguintes diretrizes e normas regulamentadoras de pesquisas envolvendo seres humanos. Recuperado de 


\section{O TRABALHO DAS PROFESSORAS NA EDUCAÇÃO INFANTIL E A APRENDIZAGEM DA CRIANÇA COM SCZV}

http://bvsms.saude.gov.br/bvs/saudelegis/cns/2013/res0466_12_12_2012.html

Souza, D. T. R (2006). Formação continuada de professores e fracasso escolar: problematizando 0 argumento da incompetência. Educação e Pesquisa, 32(3), 477-492. Recuperado de: http://www.scielo.br/pdf/ep/v32n3/a04v32n3.pdf

Veggetti, M. S. (2018). Becoming a person through innovative inclusive education. Educação, 42(3), 393-400.

Recuperado

de:

http://revistaseletronicas.pucrs.br/ojs/index.php/faced/article/view/31755/17617

Vigotski, L. S (2011). A defectologia e o estudo do desenvolvimento da educação da criança anormal. Educação e Pesquisa, 37(4), 863-869. Recuperado de: http://www.scielo.br/pdf/ep/v37n4/a12v37n4.pdf

Vigotski, L. S (2004). Teoria e método em psicologia (3a ed). São Paulo: Martins Fontes.

Vigotski, L. S. (2010). A construção do pensamento e da linguagem (2ª ed). São Paulo: Martins Fontes

Vygotsky, L. S (1996). A formação social da mente: o desenvolvimento dos processos psicológicos superiores ( $5^{\mathrm{a}}$ ed). São Paulo: Martins Fontes.

Yin. R. (2001). Estudo de caso: planejamento e métodos (2ª ed.). São Paulo: Bookman. 